\title{
Species discrimination of terrestrial processed animal proteins by laser-induced breakdown spectroscopy (LIBS) based on elemental characteristics
}

\author{
Mengyan Wang, Lujia Han, Zengling Yang, Xian Liu \\ College of Engineering. China Agricultural University (East Campus). P.O. Box 191. 17 Qing-Hua-Dong-Lu. Hai-Dian \\ District. Beijing 100083 (PR China). E-mail: 1x@cau.edu.cn
}

Received 12 September 2018, accepted 7 May 2019, available online 4 June 2019.

This article is distributed under the terms and conditions of the CC-BY License (http://creativecommons.org/licenses/by/4.0)

\begin{abstract}
Description of the subject. This research presents a novel approach for species discrimination of terrestrial processed animal proteins (PAP) using laser-induced breakdown spectroscopy (LIBS) as an alternative technique for determining feed safety. Objectives. To explore the correlation between LIBS results and elemental composition. To assess the potential of LIBS spectroscopic methods for species discrimination of terrestrial PAP.

Method. A total of 42 reliable terrestrial PAP samples of ovine, bovine, porcine, and poultry origin were analyzed and LIBS spectra were innovatively collected from the separated bone fraction. Partial least squares-discriminant analysis (PLS-DA) models were performed on the dataset.

Results. Significant differences were found in the element compositions (carbon, nitrogen, hydrogen, calcium, sodium, potassium, magnesium, zinc, strontium and barium, $p<0.05$ ) of PAP from different sources, which indicated a high potential for species discrimination. High-marked LIBS spectral characteristics (21 variables) related to six elements (calcium, sodium, magnesium, zinc, strontium and barium) for different species of terrestrial PAP samples were found out. PAP from the four tested species could be well classified with high sensitivity and specificity $(>0.90)$, while the ruminant and non-ruminant PAP could be thoroughly discriminated. For the discriminant analysis of ruminant-derived components in terrestrial PAPs, the detection of 10\%-40\% adulteration can be achieved and the correct rate is about $95 \%$.

Conclusions. This study demonstrates that LIBS can mostly exhibit the elemental composition of different terrestrial PAP, and can be a promising method for discriminating the different animal species or animal groups (ruminant/non-ruminant) involved in terrestrial PAPs.
\end{abstract}

Keywords. Spectroscopy, elements, bone meal, discrimination, feeds, adulteration.

Discrimination d'espèces de protéines animales terrestres transformées par spectroscopie de dégradation induite par laser (LIBS) basée sur les caractéristiques élémentaires

Description du sujet. Cette recherche présente une nouvelle approche pour déterminer la composition spécifique de protéines animales transformées (PAT) terrestres en utilisant la spectroscopie de décomposition induite par laser (LIBS) comme technique alternative pour déterminer la sécurité des aliments pour animaux.

Objectifs. Explorer la corrélation entre les résultats LIBS et la composition élémentaire. Évaluer le potentiel des méthodes spectroscopiques de LIBS pour la discrimination des espèces animales constitutives de PAT terrestres.

Méthode. Un total de 42 échantillons fiables de PAT terrestres d'origine ovine, bovine, porcine et avicole ont été analysés et les spectres LIBS ont été recueillis de façon innovante à partir d'une fraction osseuse séparée. Des modèles d'analyse discriminante (PLS-DA) des moindres carrés partiels ont été exécutés sur le jeu de données.

Résultats. Des différences significatives ont été observées dans les compositions d'éléments (carbone, azote, hydrogène, calcium, sodium, potassium, magnésium, zinc, strontium et baryum, $p<0,05)$ de PAT terrestres provenant de différentes sources, ce qui indique un fort potentiel de discrimination des espèces. On a découvert des caractéristiques spectrales de LIBS marquées (21 variables) liées à six éléments (calcium, sodium, magnésium, zinc, strontium et baryum) pour différentes espèces d'échantillons de PAT terrestres. Les PAT des quatre espèces testées pourraient être bien classées avec une sensibilité et une spécificité élevées $(>0,90)$, de même que les PAT de ruminants et de non-ruminants pourraient être soigneusement discriminés. L'analyse discriminante décèle à $95 \%$ une adultération à $10 \%-40 \%$ de ruminants dans des PAT terrestres . 
Conclusions. Cette étude démontre que la LIBS peut mettre en évidence la composition élémentaire de différentes sortes de PAT terrestres et s'avère être une méthode prometteuse pour identifier les différentes espèces animales ou les groupes animaux (ruminants/non-ruminants) constitutifs de PAT terrestres.

Mots-clés. Spectroscopie, élément chimique, farine d'os, discrimination, aliment pour animaux, adultération.

\section{INTRODUCTION}

With the rapid development of animal husbandry, the quality and safety of animal feed products has become much more important. Processed animal proteins (PAP) have been recognized as a valuable source of protein for animal nutrition (Lecrenier et al., 2016). However, due to the risk of bovine spongiform encephalopathy (BSE), PAP used in animal feed has been subjected to close scrutiny. Aiming at the feed safety or even human health, it is essential to identify the species of animal derived ingredients in feedstuff (Gao et al., 2018).

There are two stages for the worldwide research on the detection of PAP. During the first stage, meat and bone meal were totally prohibited as feed ingredients for all animals (EC/88/98, EC/126/2003, EC/152/2009), while light microscopy was the only official method. It can accurately detect the PAP in feedstuffs, but it is difficult to further determine the species. In 2013, the ban on non-ruminant PAP in fish feed was repealed (EC/51/2013), marking the entrance into the second stage. To implement this stage, there was an urgent need for species-specific methods for PAP detection. Therefore, polymerase chain reaction (PCR) was introduced as another official method, which can test the animal species based on specific regions of DNA strands. However, both of the officially accepted methods require tedious procedures, countless hours of analysis and technical expertise, which are less convenient for routine testing of the large quantities present in the feed trade (Fumière et al., 2009; Tena et al., 2014; Gao et al., 2017). Effective methods are still worth probing for species discrimination of PAP.

Studies have shown the presence of various elements in PAP including carbon $(\mathrm{C})$, hydrogen $(\mathrm{H})$, oxygen $(\mathrm{O})$, nitrogen $(\mathrm{N})$, calcium $(\mathrm{Ca})$, phosphorus $(\mathrm{P})$, sodium $(\mathrm{Na})$, magnesium $(\mathrm{Mg})$, potassium $(\mathrm{K})$, iron $(\mathrm{Fe})$, zinc (Zn) (Cascarosa et al., 2012). Studies of meat quality show that elemental composition can vary depending on the animal species (Georgievskii et al., 1981; Bodwell \& Anderson, 1986). However, the elemental differences in different species of animal bones are not consistent with those of meat (Bilge et al., 2016b; Yajie et al., 2017). Therefore, the complexity of PAP to be analyzed may create misinterpretations. For this reason, elemental studies focused on the bone fraction may be a more feasible choice, since the officially accepted microscopic method for PAP detection is also focused on bone fraction. Laser-induced breakdown spectroscopy (LIBS), also known as laser-induced plasma spectroscopy (LIPS), is a laser-based optical spectroscopy technique used to detect atomic, ionic and simple molecular emission signals of elements (Miziolek et al., 2006). It is simultaneously sensitive to all elements and requires minimal or no sample preparation. Coupled with multivariate analyses, LIBS has been widely applied for identification and classification purposes, such as for geomaterial classification (Sirven et al., 2007; Gottfried et al., 2009; Forni et al., 2013; Tian et al., 2014; Yu et al., 2016), detection of malignant tissues (Kaiser et al., 2012; Oztoprak et al., 2012), and discrimination of food species (Bilge et al., 2016a; Bilge et al., 2016b; Moncayo et al., 2016). However, studies on species discrimination of PAP by LIBS based on elemental characteristics remain scarce.

The objectives of this study were to explore the differences of elemental composition between different species of terrestrial PAP and to reveal the correlation between LIBS and element characteristics. LIBS spectra were innovatively collected from the separated bone fraction of terrestrial PAP, and high-marked spectral characteristics related to element composition for different species were studied. Partial least squaresdiscriminant analysis (PLS-DA) models were further established on the dataset to assess the potential of LIBS spectroscopic methods for species discrimination of terrestrial PAP.

\section{MATERIALS AND METHODS}

\subsection{Sample preparation and bone fraction extraction}

A total of 42 terrestrial PAP samples (eight ovine, ten bovine, fourteen porcine, and ten poultry) were collected for this study. Half of the samples were supplied by the national feed quality control center of China, which were obtained from the industrial retailers and producers from eight provinces in China. The rest were derived from fresh bones bought from local butchers' and were self-manufactured by an industrial process (Ockerman \& Hansen, 1999). All the samples were ground to $0.5 \mathrm{~mm}$ using an ultracentrifugal mill (ZM200 Retsch, Germany) that 
was previously decontaminated with DNA erase. To separate and concentrate the bone fraction, PAP samples were sedimented using tetrachloroethylene according EU regulation EC/51/2013 for the detection of processed animal particles via microscopy. What we call the "bone fraction" consists in the aggregation of the isolated bone particles. All samples were stored in a fridge at $4^{\circ} \mathrm{C}$ for preservation.

For the discrimination of adulterated samples, pure ruminant PAP were added into non-ruminant samples in accurate weighted proportions from 1 to $40 \%$ (w/w, $1 \%, 2 \%, 5 \%, 10 \%, 15 \%, 20 \%, 25 \%, 30 \%, 35 \%, 40 \%$ ) and total 60 blended samples (six samples per level) were prepared. These powders are thoroughly mixed at room temperature and atmospheric pressure. Then the bone fraction was extracted from mixed PAP.

\subsection{Elemental determination}

All analytical determinations were performed in duplicate, and the recorded result was the average. Carbon $(\mathrm{C})$, hydrogen $(\mathrm{H})$, oxygen $(\mathrm{O})$, nitrogen $(\mathrm{N})$, and sulphur $(\mathrm{S})$ were determined by placing the bone fraction in an Elementar Vario EL II (Vario Macro, Germany). For the mineral content determination, dried samples of the bone fraction of PAP of different animal species were digested in an Ethos Touch Control microwave digestion system (Milestore, Italy). The contents of calcium $(\mathrm{Ca})$, phosphorus $(\mathrm{P})$, sodium $(\mathrm{Na})$, magnesium $(\mathrm{Mg})$, potassium $(\mathrm{K})$, iron $(\mathrm{Fe})$, zinc $(\mathrm{Zn})$, strontium $(\mathrm{Sr})$, barium $(\mathrm{Ba})$, and gadolinium (Gd) in the digested samples were determined using inductively coupled plasma mass spectroscopy (Agilent 7500, USA) with for each a single element standard solution at a concentration of $1,000 \mathrm{ppm}$ (Chemical Metrology \& Analytical Science Division, China).

\subsection{LIBS instrumentation and spectral analysis}

The bone fraction from each PAP sample was placed in an aluminium cover that had a loading size of $\varnothing 30 \mathrm{~mm} \times 7 \mathrm{~mm}$, and then were tableted at $20 \mathrm{t}$ of pressure. A commercial LIBS system (ChemReveal $^{\mathrm{TM}}$-3764, TSI, USA) was used for the spectral analysis. The laser beam from a Q-switched Nd: YAG laser operating at 1,064 $\mathrm{nm}$ was used to create the plasma on the surface of the tablets of the bone fraction. The best signal-to-background ratio was achieved at an 80-mJ pulse energy with a repetition rate of $2 \mathrm{~Hz}$ and a gate delay of $1 \mu \mathrm{s}$. The wavelength range used was approximately 190 to $950 \mathrm{~nm}$. To minimize the influence of sample heterogeneity and laser energy fluctuations, 126 shots $(14 \times 9)$ with a step size of $1.5 \mathrm{~mm}$ were performed on each sample. The time required to perform an analysis of each sample is less than 5 min. ChemLytics ${ }^{\mathrm{TM}}$ software was used to obtain the average spectra and search spectral peaks.

\subsection{Statistical analysis and multivariate evaluation}

Each element content was statistically compared using one-way ANOVA in the SPSS 20.0 program (SPSS, Inc., USA). A confidence level was set at $95 \%$ $(p<0.05)$. All data processing and modelling in the multivariate data analysis were conducted on Matlab 2012a (The Mathworks, Inc., USA) using the PLS Toolbox 3.5 (Eigenvector Research, Inc., Manson WA).

The element profile and LIBS spectra of several bone fractions were investigated based on principal component analysis (PCA). Partial least squaresdiscriminant (PLS-DA) were further applied to the dataset of whole LIBS spectra and the selected spectra, respectively. At first, all data were divided into four categories according to animal species. The applied data pretreatments were standard normal variate (SNV) and mean centre (MC). Then PLS-DA discrimination models were established based on LIBS spectra via internal cross-validation (leave one out). In addition, other PLS-DA discrimination models were established when the samples were divided into two categories (ruminant and non-ruminant).Values of sensitivity (percentage of target samples correctly classified), specificity (percentage of non-target samples correctly classified) and classification error (the average value of the mis-classified samples) were calculated for the evaluation of discriminations (Ockerman \& Hansen, 1999; Abbas et al., 2009).

For the discrimination of ruminant adulteration based on LIBS spectra, several PLS-DA models were established in the order of proportion of addition. When the adulteration ratio reached between $1 \%$ and 40\%, 24 ruminant samples and 60 blended samples described in Section 2.1. were considered in the PLS-DA model. The adulterations were further separated into subsets, and more blended samples within the adulteration ratio range were added into the corresponding subsets to meet the requirements of sample size in the models. Samples were divided into calibration and validation sets by taking every fourth sample ascending in reference data into validation set, while the others comprised the calibration set. The rate of correct discrimination was calculated for the discrimination of adulterated samples. If a sample of pure non-ruminant was judged to be adulterated, it was marked as false positive; if the adulterated sample is judged as non-ruminant, it was marked as false negative. The total number of samples minus the number of false positives and false negatives was defined as the number of correctly discriminated samples (Xu et al., 2016). 


\section{RESULTS}

\subsection{Difference analysis of elemental characteristics}

The elemental analysis clearly showed the presence of various elements in all bone samples, including $\mathrm{C}, \mathrm{H}$, $\mathrm{O}, \mathrm{N}, \mathrm{S}, \mathrm{Ca}, \mathrm{P}, \mathrm{Na}, \mathrm{Mg}, \mathrm{K}, \mathrm{Fe}, \mathrm{Zn}, \mathrm{Sr}$, and Ba (Table 1). The mean and standard deviations (SDs) were calculated to analyze the elemental concentrations on bone fractions of different species. Upon comparing all of the elements present in the tested samples, it is observed that $\mathrm{Ca}$ was most abundant. Besides, the content of gadolinium (Gd) was generally low $(<0.5 \mathrm{ppm})$ and was even below the detection limit of ICP-MS.

The majority of individual elemental composition (C, N, H, Ca, $\mathrm{Na}, \mathrm{K}, \mathrm{Mg}, \mathrm{Zn}, \mathrm{Sr}$, and $\mathrm{Ba}$ ) was statistically different $(p<0.05)$ among the tested species (Table 1). The concentrations of $\mathrm{Sr}$ and $\mathrm{Ba}$ in the ruminant (bovine and ovine) bone fractions were significantly higher than in non-ruminant samples (porcine and poultry), whereas $\mathrm{C}$ exhibited the reverse trend. Moreover, compared with the poultry samples, porcine bone fraction possessed distinctly higher amounts of $\mathrm{Ca}$ and $\mathrm{Na}$ and lower amounts of $\mathrm{K}$ and $\mathrm{Zn}$. Significantly higher contents of $\mathrm{Mg}$ and $\mathrm{Sr}$ and significantly lower contents of $\mathrm{N}$ and $\mathrm{H}$ were detected in ovine bone fractions compared with bovine samples.

\subsection{Species discrimination based on elemental characteristics}

In order to classify the bone fractions originating from different animal species based on the elemental characteristics, the concentrations of ten kinds of specific elements (C, N, H, Ca, Na, K, Mg, Zn, Sr, and Ba) were evaluated by PCA, which is illustrated in figure 1. In figure 1a, the first two principal components explain $41.09 \%$ and $17.17 \%$ of the total variance. Although non-ruminant and ruminant samples were nearly separated, the overlap of bovine and ovine samples were considered difficult to distinguish. In addition, the loading plot (Figure 1b) shows the correlation and contribution rates of the elements for the distributions in the score plot (Figure 1a). The distributions of poultry, mostly at the negative end of $\mathrm{PC} 1$ and $\mathrm{PC} 2$, are attributed to $\mathrm{K}$ and $\mathrm{Zn}$, while ruminant spreads mostly along the positive direction of $\mathrm{PC} 1$ and is attributed to $\mathrm{Ba}, \mathrm{Sr}$, and $\mathrm{Ca}$. Overall, species discrimination of PAP based on elemental characteristics of their bone fraction is feasible.

\subsection{Correlation analysis between LIBS spectra and element characteristics}

Each LIBS spectrum is an average of 126 original spectra and figure 2 displays the averaged spectrum for a typical sample of a bone fraction. According

Table 1. Elemental compositions and statistical analysis of the bone fraction from different terrestrial animal species - Compositions élémentaires et analyse statistique de la fraction osseuse de différentes espèces animales terrestres.

\begin{tabular}{lcccc}
\hline Elements & Ovine sample & Bovine sample & Porcine sample & Poultry sample \\
\hline $\mathrm{C}\left(\mathrm{g} \cdot \mathrm{kg}^{-1}\right)$ & $152.47 \pm 12.70^{\mathrm{a}}$ & $155.90 \pm 2.47^{\mathrm{a}}$ & $167.05 \pm 7.97^{\mathrm{b}}$ & $164.00 \pm 16.00^{\mathrm{b}}$ \\
$\mathrm{N}\left(\mathrm{g} \cdot \mathrm{kg}^{-1}\right)$ & $42.64 \pm 1.58^{\mathrm{a}}$ & $48.57 \pm 4.15^{\mathrm{b}}$ & $42.58 \pm 3.43^{\mathrm{a}}$ & $42.72 \pm 3.43^{\mathrm{a}}$ \\
$\mathrm{H}\left(\mathrm{g} \cdot \mathrm{kg}^{-1}\right)$ & $21.92 \pm 2.85^{\mathrm{a}}$ & $24.51 \pm 1.66^{\mathrm{b}}$ & $25.91 \pm 1.86^{\mathrm{b}}$ & $25.18 \pm 2.32^{\mathrm{b}}$ \\
$\mathrm{S}\left(\mathrm{g} \cdot \mathrm{kg}^{-1}\right)$ & $3.32 \pm 0.14^{\mathrm{a}}$ & $3.90 \pm 0.24^{\mathrm{a}}$ & $3.25 \pm 0.87^{\mathrm{a}}$ & $4.39 \pm 0.20^{\mathrm{a}}$ \\
$\mathrm{O}\left(\mathrm{g} \cdot \mathrm{kg}^{-1}\right)$ & $158.76 \pm 17.23^{\mathrm{a}}$ & $150.51 \pm 6.27^{\mathrm{a}}$ & $144.83 \pm 15.97^{\mathrm{a}}$ & $161.65 \pm 13.72^{\mathrm{a}}$ \\
$\mathrm{Ca}\left(\mathrm{g} \cdot \mathrm{kg}^{-1}\right)$ & $218.68 \pm 12.22^{\mathrm{a}}$ & $215.24 \pm 10.88^{\mathrm{a}}$ & $206.92 \pm 9.03^{\mathrm{a}}$ & $190.56 \pm 8.27^{\mathrm{b}}$ \\
$\mathrm{P}\left(\mathrm{g} \cdot \mathrm{kg}^{-1}\right)$ & $106.49 \pm 7.36^{\mathrm{a}}$ & $97.77 \pm 10.34^{\mathrm{a}}$ & $101.24 \pm 7.26^{\mathrm{a}}$ & $103.00 \pm 5.67^{\mathrm{a}}$ \\
$\mathrm{Na}\left(\mathrm{g} \cdot \mathrm{kg}^{-1}\right)$ & $8.75 \pm 1.27^{\mathrm{ab}}$ & $10.90 \pm 3.56^{\mathrm{ab}}$ & $12.34 \pm 3.98^{\mathrm{b}}$ & $9.02 \pm 3.82^{\mathrm{a}}$ \\
$\mathrm{K}\left(\mathrm{g} \cdot \mathrm{kg}^{-1}\right)$ & $1.35 \pm 0.25^{\mathrm{a}}$ & $1.52 \pm 0.76^{\mathrm{a}}$ & $1.83 \pm 0.80^{\mathrm{a}}$ & $4.75 \pm 1.46^{\mathrm{b}}$ \\
$\mathrm{Mg}\left(\mathrm{g} \cdot \mathrm{kg}^{-1}\right)$ & $6.43 \pm 0.83^{\mathrm{a}}$ & $5.18 \pm 0.79^{\mathrm{b}}$ & $5.48 \pm 0.30^{\mathrm{b}}$ & $5.12 \pm 0.97^{\mathrm{b}}$ \\
$\mathrm{Fe}\left(\mathrm{g} \cdot \mathrm{kg}^{-1}\right)$ & $0.32 \pm 0.34^{\mathrm{a}}$ & $0.44 \pm 0.30^{\mathrm{a}}$ & $1.20 \pm 0.87^{\mathrm{a}}$ & $0.14 \pm 0.04^{\mathrm{a}}$ \\
$\mathrm{Zn}\left(\mathrm{g} \cdot \mathrm{kg}^{-1}\right)$ & $0.17 \pm 0.01^{\mathrm{ac}}$ & $0.14 \pm 0.03^{\mathrm{a}}$ & $0.19 \pm 0.02^{\mathrm{c}}$ & $0.29 \pm 0.05^{\mathrm{b}}$ \\
$\mathrm{Sr}\left(\mathrm{mg} \cdot \mathrm{kg}^{-1}\right)$ & $312.40 \pm 72.74^{\mathrm{a}}$ & $238.39 \pm 69.30^{\mathrm{b}}$ & $124.90 \pm 50.5^{\mathrm{c}}$ & $53.40 \pm 21.94^{\mathrm{c}}$ \\
$\mathrm{Ba}\left(\mathrm{mg} \cdot \mathrm{kg}^{-1}\right)$ & $167.75 \pm 53.75^{\mathrm{a}}$ & $184.92 \pm 83.14^{\mathrm{a}}$ & $34.58 \pm 26.33^{\mathrm{b}}$ & $10.60 \pm 4.84^{\mathrm{b}}$ \\
\hline
\end{tabular}

${ }^{\mathrm{a}-\mathrm{c}}$ : Means within a row with different superscripts differ $(p<0.05)$ - les moyennes sur une même ligne avec différents exposants sont différentes $(\mathrm{p}<0,05)$. 

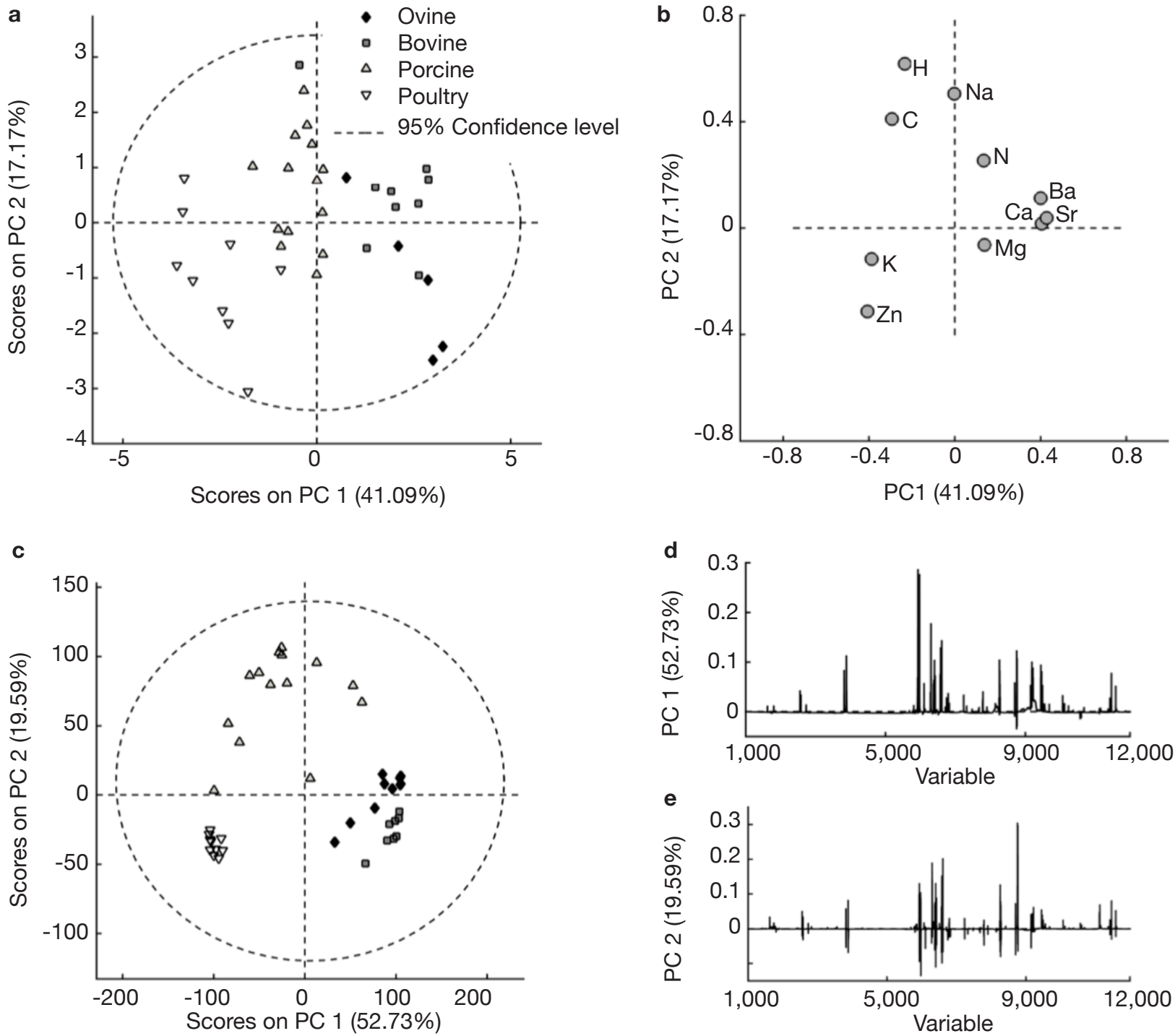

Figure 1. Score and loading plots of principal component analysis based on the concentrations of ten kinds of specific elements (a, b) and laser-induced breakdown spectra (LIBS) of the bone fractions from processed animal proteins (PAP) of different terrestrial animal species $(\mathbf{c}, \mathbf{d}, \mathbf{e})$ - Graphiques des scores et des loading en analyse de composantes principales basées sur les concentrations de dix types d'éléments spécifiques $(\boldsymbol{a}, \boldsymbol{b})$ et de spectres de dégradation induite par laser (LIBS) de particules d'os provenant de protéines animales transformées $(P A T)$ de différentes espèces animales terrestres $(\boldsymbol{c}, \boldsymbol{d}, \boldsymbol{e})$.

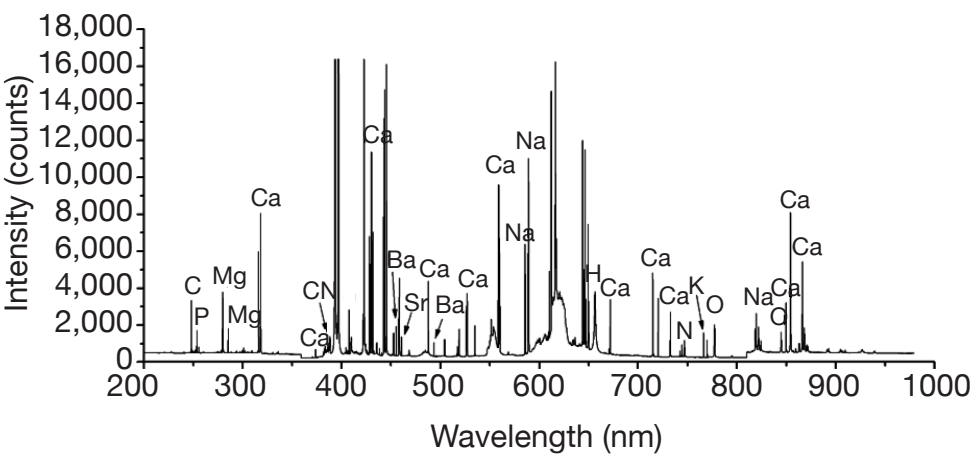

Figure 2. Representative laser-induced breakdown spectrum (LIBS) of a bovine bone fraction - Spectre de dégradation induite par laser (LIBS) représentatif d'une fraction osseuse de bovin. to the National Institute of Standards and Technology (NIST) atomic spectra database, these profiles contain atomic and ionic lines of $\mathrm{C}, \mathrm{O}, \mathrm{N}, \mathrm{H}, \mathrm{Ca}, \mathrm{P}, \mathrm{Na}, \mathrm{K}, \mathrm{Mg}, \mathrm{Sr}$, and $\mathrm{Ba}$ within the wavelength range of 190-950 nm. Emissions from the $\mathrm{CN}$ molecular band were observed at approximately $388.3 \mathrm{~nm}$ due to carbon recombination with atmospheric nitrogen (Akpovo et al., 2013).

Because the spectral line intensity of any element is directly proportional to its concentration in the target sample (Tripathi et al., 2015), the elemental difference between bone fraction samples can be 
expressed effectively by the intensity in the LIBS spectra. In order to explore the correlation between LIBS and element characteristics, the section spectrum of different bone fractions is shown in figure 3. The spectral lines of $\mathrm{Ca}$ are abundant; for instance, the peaks at $315.89 \mathrm{~nm}$ and $317.93 \mathrm{~nm}$ in mammalian samples (porcine, bovine and ovine) were more intense than in poultry bone fraction. Furthermore, the LIBS spectra provided a clear difference at $407.77 \mathrm{~nm}$ and $455.40 \mathrm{~nm}$ between the ruminant (bovine and ovine) and non-ruminant (porcine and poultry) samples since the contents of $\mathrm{Sr}$ and $\mathrm{Ba}$ in the ruminants were significantly higher. Since porcine bone fractions exhibited higher amounts of $\mathrm{Na}$ among the non-ruminant samples, the intensity at $589.00 \mathrm{~nm}$ and $589.59 \mathrm{~nm}$ were higher than in poultry samples. In addition, the peaks at $279.55 \mathrm{~nm}, 280.27 \mathrm{~nm}$ and $285.21 \mathrm{~nm}$ in ovine samples were more intense than the ones in poultry samples. Whereas, the peaks at $766.49 \mathrm{~nm}$ and $769.9 \mathrm{~nm}$ in ovine samples presented the opposite tendency. It is indicated that $\mathrm{Mg}$ and $\mathrm{K}$ may contribute to the differences.
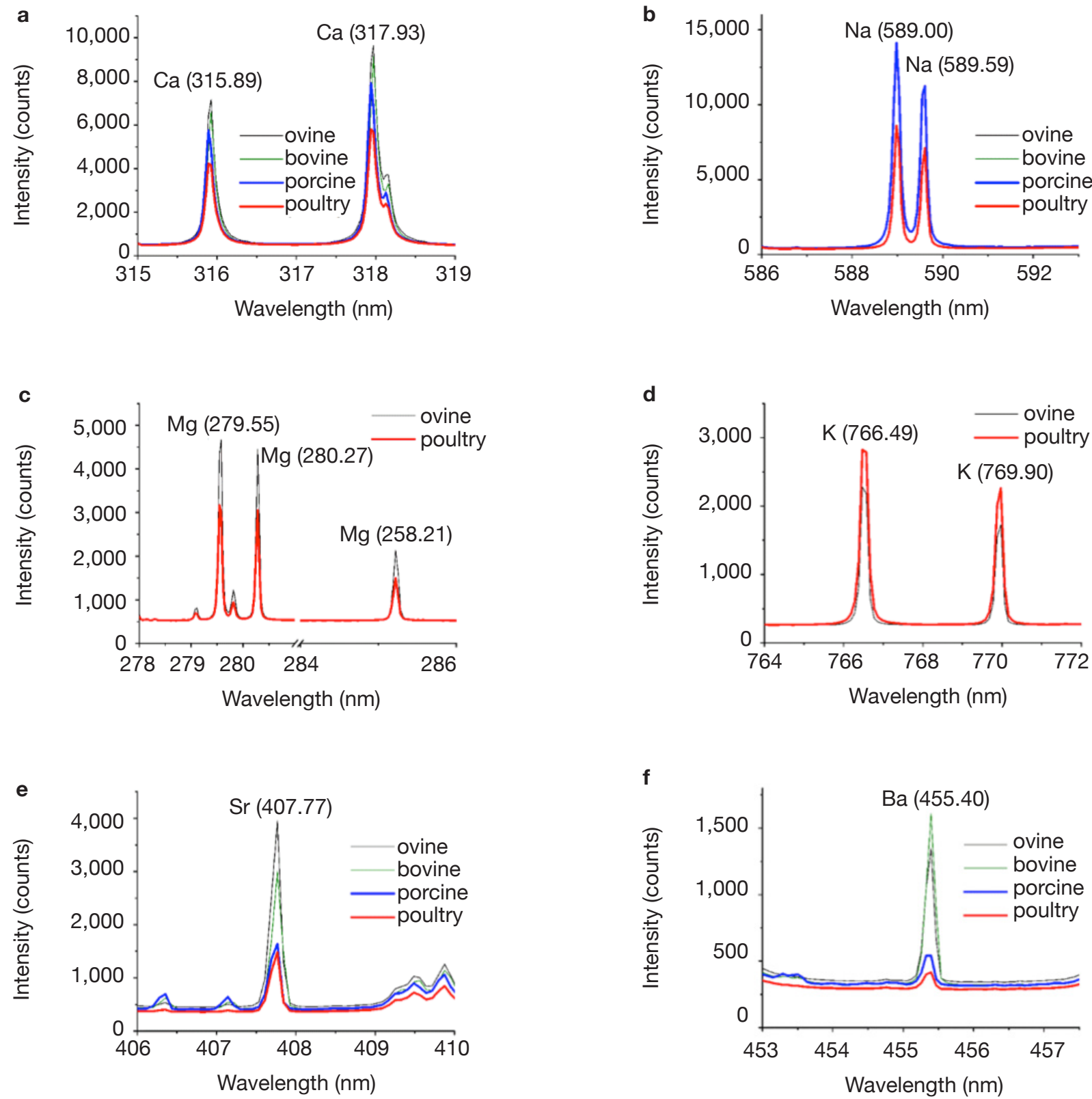

Figure 3. Section spectra of the bone fraction from processed animal proteins (PAP) of different terrestrial animal species - Spectres de section de la fraction osseuse issue de protéines animales transformées (PAT) de différentes espèces animales terrestres. 


\subsection{Species discrimination based on LIBS spectral characteristics}

The broadband LIBS spectra consist of 12,990 intensity channels ranging from $190 \mathrm{~nm}$ to $950 \mathrm{~nm}$, and each channel was used as an input variable in the PCA and PLS-DA model. As shown in figure 1c, the variation between poultry and ruminant samples is expressed by PC1. The loading plot (Figure 1d) indicates high concentrations of $\mathrm{Ca}$ in the ruminant samples compared to poultry samples. Meanwhile, PC2 placed the porcine samples on the positive side and poultry samples on negative side. The distributions of porcine, significantly at the positive end of $\mathrm{PC} 2$, are mostly attributed to $\mathrm{Na}$ (Figure 1e). In addition, bovine and ovine samples were clustered in figure 1c, which indicated higher discrimination power of LIBS profiles than that of element profile (Figure 1a).

To confirm the obtained separation, PLS-DA discrimination models were then established based on the whole LIBS spectra and selected high-marked spectra. Table 2 shows the PLS-DA discrimination results, including the values of sensitivity, specificity and classification error, which were determined via internal cross-validation (leave one out). Based on whole LIBS spectra, discrimination 1 indicated a clear separation between porcine and poultry bone fractions compared to the remaining samples for which the sensitivity, specificity and classification error were 1,1 and 0 , respectively, whereas the discrimination values of the ovine or bovine samples were not optimal. This result is very similar to the groupings observed in figure 1. Moreover, discrimination 2 (whole spectra) presented an ideal situation with a perfect diagnostic classification of the ruminant and non-ruminant samples, leading to $100 \%$ discrimination without any exception.
Because the majority of the variables in the whole spectra PLS-DA model may not significantly contribute to the differences between species, down-selecting the variables that were used as inputs into the PLS-DA model should produce a more efficient and robust model (De Lucia \& Gottfried, 2011). After a spectral peak search resulting from the LIBS emission, genetic algorithms (GA), which were applied successfully in previous papers (Leardi \& Gonzalez, 1998), were used to select the most informative spectra in this study. The wavelength and matched elemental information of high-marked variables were selected from whole LIBS spectra and are shown in table 3.

In table 2, discrimination 1 (high-marked spectra) shows that terrestrial animal species present relatively good values of sensitivity and specificity, which all exceeded 0.9 and were close to 1 , and lower classification error (close to 0), which indicates a good classification of the bone fractions according to their animal origin. Moreover, discrimination 2 (highmarked spectra) works as well as the whole spectra PLS-DA model, which can satisfy the demand of discrimination.

\subsection{Detection of ruminant-derived components in PAPs based on LIBS spectral characteristics}

LIBS spectra of the bone fraction separated from raw non-ruminant terrestrial PAPs and adulterated samples $(1 \%-40 \%)$ were subjected to the PLS-DA algorithm. The calibration model was established using crossvalidation and independent validation was predicted to assess model accuracy. The detection limits for ruminant adulteration were explored. Results of calibration indicated that correct discrimination rates of ruminant adulteration are both higher than $92 \%$, with several false positive and false negative samples. Getting rid

Table 2. Results of partial least squares-discriminant analysis (PLS-DA) based on laser-induced breakdown spectroscopy (LIBS) spectra performed on the bone fraction from processed animal proteins (PAP) of different terrestrial animal species - Résultats de la discrimination des moindres carrés partiels (PLS-DA) basée sur la spectroscopie de dégradation induite par laser (LIBS) sur la fraction osseuse de protéines animales transformées (PAT) de différentes espèces animales terrestres.

\begin{tabular}{|c|c|c|c|c|c|c|c|}
\hline \multirow[t]{2}{*}{ Class } & & \multicolumn{4}{|c|}{ Discrimination 1} & \multicolumn{2}{|c|}{ Discrimination 2} \\
\hline & & Ovine & Bovine & Porcine & Poultry & Ruminant & Non-ruminan \\
\hline \multirow[t]{3}{*}{ Whole spectra } & Sensitivity (CV) & 0.90 & 0.88 & 1.00 & 1.00 & 1.00 & 1.00 \\
\hline & Specificity (CV) & 0.84 & 0.97 & 1.00 & 1.00 & 1.00 & 1.00 \\
\hline & Classification error (CV) & 0.13 & 0.08 & 0.00 & 0.00 & 0.00 & 0.00 \\
\hline \multirow[t]{3}{*}{ High-marked spectra } & Sensitivity (CV) & 0.90 & 1.00 & 1.00 & 1.00 & 1.00 & 1.00 \\
\hline & Specificity (CV) & 0.91 & 0.97 & 1.00 & 1.00 & 1.00 & 1.00 \\
\hline & Classification error (CV) & 0.10 & 0.02 & 0.00 & 0.00 & 0.00 & 0.00 \\
\hline
\end{tabular}

CV: cross-validation - validation croisée. 
Table 3. Wavelength and matched elemental information of high-marked variables selected from whole LIBS spectra - Longueur d'onde et informations élémentaires appariées des variables marquées de haute qualité sélectionnées dans des spectres LIBS entiers.

\begin{tabular}{|c|c|}
\hline Central wavelength (nm) & Possible element $^{1}$ \\
\hline 279.547 & Mg II (279.553) \\
\hline 280.281 & Mg II (280.270) \\
\hline 285.221 & Mg I (285.213) \\
\hline 315.892 & Ca II (315.887) \\
\hline 317.938 & Ca II (317.933) \\
\hline 370.636 & Ca II (370.603) \\
\hline 373.718 & Ca II (373.690) \\
\hline 407.767 & Sr II (407.771) \\
\hline 455.396 & $\mathrm{Ba}$ II (455.403) \\
\hline 460.746 & Sr I (460.733) \\
\hline 487.780 & Ca I (487.813) \\
\hline 493.406 & Ba II (493.408) \\
\hline 589.035 & $\mathrm{Na} I(588.995)$ \\
\hline 589.604 & $\mathrm{Na} I(589.592)$ \\
\hline 714.808 & $\mathrm{Ca} I(714.815)$ \\
\hline 720.283 & Ca I (720.219) \\
\hline 766.478 & K I (766.490) \\
\hline 769.874 & K I (769.896) \\
\hline 849.772 & Ca II (849.802) \\
\hline 854.180 & Ca II (854.209) \\
\hline 866.185 & Ca II (866.214) \\
\hline
\end{tabular}

I: atomic spectral lines - lignes spectrales atomiques; II: ionic spectral lines - lignes spectrales ioniques.

of the adulterated samples of $1 \%$ ruminant in nonruminant samples, PLS-DA discriminant models were re-established for the adulteration percentage range of $5 \%-40 \%$, but the result of independent validation was not very satisfactory with the correct rate rising to $85.71 \%$. For adulteration percentage range of $10 \%-40 \%$, results of calibration showed that correct

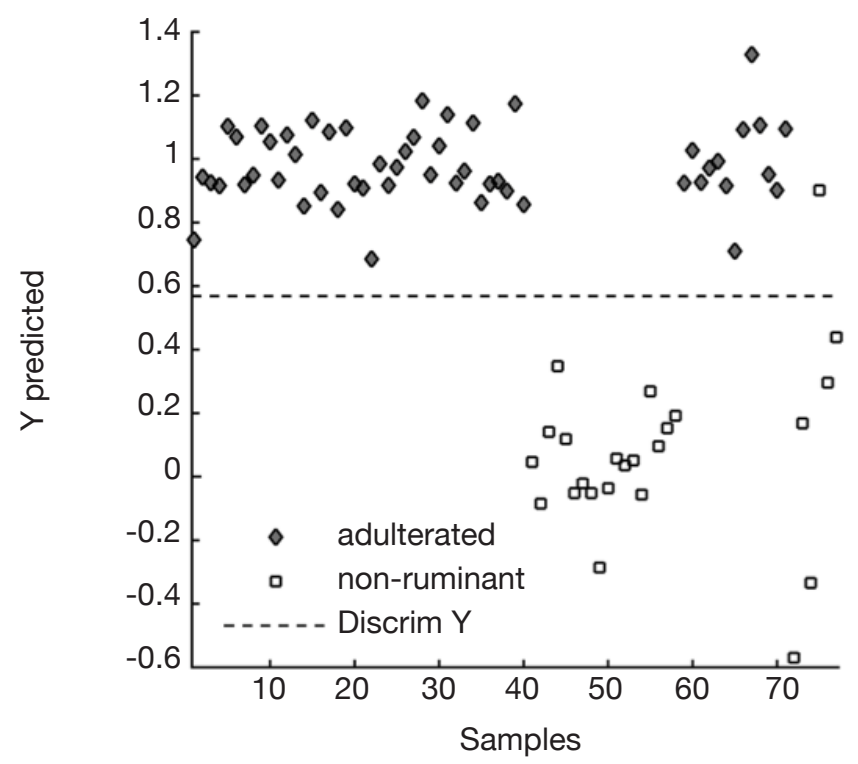

Figure 4. Partial least squares-discriminant analysis (PLSDA) of ruminant adulteration (10\%-40\%) in non ruminant terrestrial processed animal proteins (PAP) based on laserinduced breakdown spectra (LIBS) - Discrimination des moindres carrés partiels (PLS-DA) de la fortification par du matériel ruminant (10\%-40\%) de protéines animales transformées (PAT) terrestres de non-ruminants sur base des spectres de dégradation induite par laser (LIBS).

discrimination rate was $100 \%$, with none false positive and false negative sample. In addition, good validation results were acquired with only one false negative sample in figure $\mathbf{4}$ and the correct discrimination rate was about $95 \%$. Furthermore, results of three groups for different adulteration ratio in table $\mathbf{4}$ indicated that lower concentration samples were more likely to be misclassified. It is concluded that LIBS can be used to detect the ruminant-derived components in PAPs.

\section{DISCUSSION}

The results of previous experiments showed that the element information of raw PAP in different samples

Table 4. Results of partial least squares-discriminant analysis (PLS-DA) based on laser-induced breakdown spectroscopy (LIBS) - Résultats de la discrimination des moindres carrés partiels (PLS-DA) basée sur la spectroscopie de dégradation induite par laser (LIBS).

\begin{tabular}{llllllll}
\hline $\begin{array}{l}\text { Adulteration } \\
\text { ratio }\end{array}$ & \begin{tabular}{l} 
Calibration \\
\cline { 2 - 4 }
\end{tabular} & $\begin{array}{l}\text { Number of } \\
\text { false positive }\end{array}$ & $\begin{array}{l}\text { Number of } \\
\text { false negative }\end{array}$ & $\begin{array}{l}\text { Correct } \\
\text { discrimination }(\%)\end{array}$ & $\begin{array}{l}\text { Validation } \\
\text { fumber of }\end{array}$ \\
\hline $1 \%-5 \%$ & 2 & 3 & 83.33 & 2 & $\begin{array}{l}\text { Number of } \\
\text { false negative }\end{array}$ & $\begin{array}{l}\text { Correct } \\
\text { discrimination }(\%)\end{array}$ \\
\hline $10 \%-20 \%$ & 0 & 0 & 100.00 & 1 & 3 & 58.33 \\
$25 \%-40 \%$ & 0 & 0 & 100.00 & 0 & 0 & 91.67 \\
\hline
\end{tabular}


of terrestrial species was different mainly due to the uncertainty of the proportion of fresh bone. Therefore, elemental analysis focusing on the bone fraction issued from terrestrial PAP was conducted in this study. After bone fraction extraction, real PAP samples and self-manufactured ones of the same species show no significant difference in elemental profile as well as LIBS spectra.

The organic contents of $\mathrm{C}$ and $\mathrm{H}$ were relatively low and the mineral contents of $\mathrm{Ca}, \mathrm{P}$, and $\mathrm{Mg}$ were greater in this study compared with the existing results of the elemental determination of PAP (Cascarosa et al., 2012), which may be attributed to bone fraction extraction from PAP. The concentrations of $\mathrm{Sr}$ and $\mathrm{Ba}$ in ruminants were significantly higher, which is probably because of grazing diet and differences in gastrointestinal tracts just as the enrichment of $\mathrm{Sr} /$ $\mathrm{Ca}$ and $\mathrm{Ba} / \mathrm{Ca}$ ratios in ruminant fossil bone has been elucidated in geochemistry (Domingo \& Grimes, 2012). The difference analysis of elemental characteristics reveals a high potential for species discrimination based on elemental characteristics.

Combined with multivariate data analysis (PCA and PLS-DA), LIBS were successfully applied to determinate ruminants. Furthermore, the discrimination of high-marked spectra presented a relatively better result compared to whole spectra, with sensitivity and specificity both above 0.9 . This phenomenon illustrated that variables from high-marked spectra enhance their contribution to the classification of the whole LIBS spectra and helped in the differentiation into the different species. Significant differences in samples from different species were revealed for ten different elements ( $\mathrm{C}, \mathrm{N}, \mathrm{H}, \mathrm{Ca}, \mathrm{Na}, \mathrm{K}, \mathrm{Mg}, \mathrm{Zn}, \mathrm{Sr}$, and $\mathrm{Ba}$ ), while high-marked spectra only involved six of them (Ca, $\mathrm{Na}, \mathrm{Mg}, \mathrm{K}, \mathrm{Sr}$, and $\mathrm{Ba})$. The main reasons are as follows:

- none of the emission signals of $\mathrm{Zn}$ were detected under our spectral conditions;

- the species differences for the $\mathrm{C}$ and $\mathrm{N}$ spectral line intensities were inconsistent with the results of the elemental analysis due to the reaction of $\mathrm{C}+\mathrm{N}_{2} \leftrightarrow$ $\mathrm{CN}+\mathrm{N}$ (Dong et al., 2011);

- although there was an extremely low content in the samples, Gd may affect the spectral peak of $656.36 \mathrm{~nm}$, which has been identified as $\mathrm{H} \mathrm{I}$ $(656.28 \mathrm{~nm})$ and results from the potential existence of Gd I (656.48 nm). Compared with the analytical results of the elemental composition differences from different species, the LIBS spectral characteristics performed similarly, which revealed the mechanism of species discrimination based on the elemental LIBS characteristics.

By increasing the number of dots and the disk area, the discrimination power of the method may be further improved theoretically. Relying greatly on the elemental information of PAPs, the method is only employed for the species discrimination of the feedstock nowadays. This study attempts to explore new methods based on bone fraction and is the basis for future research on combination techniques based on different components of PAPs. Compound feeds with mineral ingredients and additives may have large interferences on this method due to variations in elemental composition.

\section{CONCLUSIONS}

In this study, the different kinds of bone fractions separated from PAP samples presented clearly diverse LIBS elemental characteristics. It is indicated that PLS-DA model based on high-marked LIBS spectra was satisfactorily applied to differentiate the tested species, including 21 wavelength points related to six elements ( $\mathrm{Ca}, \mathrm{Na}, \mathrm{Mg}, \mathrm{K}, \mathrm{Sr}$, and $\mathrm{Ba})$ selected by GA. For discriminant analysis of ruminant-derived components in PAPs, the correct rate to detect $10 \%$ $40 \%$ adulteration was about $95 \%$. Given that LIBS can effectively analyze the elemental specificity of terrestrial PAPs, it may be considered as a promising analytical methodology for its discrimination into the animal species or groups from which it originates.

\section{Acknowledgements}

This research was supported by National Key R\&D Program of China (2017YFE0115400) and National Key Research and Development Program of China (No. 2016YFE0112800).

\section{Bibliography}

Abbas O. et al., 2009. Assessment of the discrimination of animal fat by FT-Raman spectroscopy. J. Mol. Struct., 924, 294-300.

Akpovo C.A. et al., 2013. Regional discrimination of oysters using laser-induced breakdown spectroscopy. Anal. Methods, 5(16), 3956.

Bilge G. et al., 2016a. Determination of whey adulteration in milk powder by using laser induced breakdown spectroscopy. Food Chem., 212, 183-188.

Bilge G. et al., 2016b. Identification of meat species by using laser-induced breakdown spectroscopy. Meat Sci., 119, 118-122.

Bodwell C.E. \& Anderson B.A., 1986. Nutritional composition and value of meat and meat products. San Diego, CA, USA: Academic Press, 321-369.

Cascarosa E., Gea G. \& Arauzo J., 2012. Thermochemical processing of meat and bone meal: a review. Renewable Sustainable Energy Rev., 16(1), 942-957.

De Lucia F.C. \& Gottfried J.L., 2011. Influence of variable selection on partial least squares discriminant analysis 
models for explosive residue classification. Spectrochim. Acta, Part B, 66(2), 122-128.

Domingo L. \& Grimes S.T., 2012. Trace element analyses indicative of paleodiets in Middle Miocene mammals from the Somosaguas site (Madrid, Spain). Geol. Acta, 10(3), 239-247.

Dong M. et al., 2011. Experimental study on the characteristics of molecular emission spectroscopy for the analysis of solid materials containing C and N. Opt. Express, 19(18), 17021-17029.

Forni O. et al., 2013. Independent component analysis classification of laser induced breakdown spectroscopy spectra. Spectrochim. Acta, Part B, 86, 31-41.

Fumière O. et al., 2009. Methods of detection, species identification and quantification of processed animal proteins in feedingstuffs. Biotechnol. Agron. Soc. Environ., 13(S), 59-70.

Gao F. et al., 2017. A novel FT-IR spectroscopic method based on lipid characteristics for qualitative and quantitative analysis of animal-derived feedstuff adulterated with ruminant ingredients. Food Chem., 237, 342-349.

Gao F. et al., 2018. Analytical raman spectroscopic study for discriminant analysis of different animal-derived feedstuff: understanding the high correlation between raman spectroscopy and lipid characteristics. Food Chem., 240, 989-996.

Georgievskii V.I., Annenkov B.N. \& Samokhin V.T., 1981. Mineral composition of bodies and tissues of animals. In: Mineral nutrition of animals. Sevenoaks, UK: Butterworth \& Co., 69-77.

Gottfried J.L.,Harmon R.S.,DeLucia F.C.\& Miziolek A.W., 2009. Multivariate analysis of laser-induced breakdown spectroscopy chemical signatures for geomaterial classification. Spectrochim. Acta, Part B, 64(10), 10091019.

Kaiser J. et al., 2012. Trace elemental analysis by laserinduced breakdown spectroscopy-Biological applications. Surf. Sci. Rep., 67(11-12), 233-243.

Leardi R. \& Gonzalez A.L., 1998. Genetic algorithms applied to feature selection in PLS regression how and when to use them. Chemom. Intell. Lab. Syst., 41(2), 195-207.

Lecrenier M.C. et al., 2016. Identification of specific bovine blood biomarkers with a non-targeted approach using
HPLC ESI tandem mass spectrometry. Food Chem., 213, 417-424.

Miziolek A.W., Palleschi V. \& Schechter I., 2006. Laserinduced breakdown spectroscopy fundamentals and applications. New York, NY, USA: Cambridge University Press.

Moncayo S. et al., 2016. Classification of red wine based on its protected designation of origin (PDO) using laserinduced breakdown spectroscopy (LIBS). Talanta, 158 , 185-191.

Ockerman H.W. \& Hansen C.L., 1999. Animal by-product processing \& utilization. Boca Raton, FL, USA: CRC Press.

Oztoprak B.G. et al., 2012. Analysis and classification of heterogeneous kidney stones using laser-induced breakdown spectroscopy (LIBS). Appl. Spectrosc., 66(11), 1353-1361.

Sirven J.-B. et al., 2007. Feasibility study of rock identification at the surface of Mars by remote laserinduced breakdown spectroscopy and three chemometric methods. J. Anal. At. Spectrom., 22(12), 1471.

Tena N. et al., 2014. Differentiation of meat and bone meal from fishmeal by near-infrared spectroscopy: extension of scope to defatted samples. Food Control, 43, 155-162.

Tian Y. et al., 2014. Comparative investigation of partial least squares discriminant analysis and support vector machines for geological cuttings identification using laser-induced breakdown spectroscopy. Spectrochim. Acta, Part B, 102, 52-57.

Tripathi D.K. et al., 2015. An efficient approach of laser induced breakdown spectroscopy (LIBS) and ICAP-AES to detect the elemental profile of Ocimum L. species. Biocatal. Agric. Biotechnol., 4(4), 471-479.

$\mathrm{Xu}$ L. et al., 2016. Discriminant analysis of terrestrial animal fat and oil adulteration in fish oil by infrared spectroscopy. Int. J. Agric. Biol. Eng., 9(3), 179-185.

Yajie L.I. et al., 2017. Production and properties of four kinds of nano-sized bone products. Food Sci., 38(5), 38-44.

Yu K.Q., Zhao Y.R., Liu F. \& He Y., 2016. Laser-induced breakdown spectroscopy coupled with multivariate chemometrics for variety discrimination of soil. Sci. Rep., 6, 27574.

(29 ref.) 